\title{
Analisis Kompetensi Kerja Tukang Plester di Kota Palu
}

\author{
A. Asnudin ${ }^{\mathrm{a} *}$, M.A. Ridwan ${ }^{\mathrm{b}}$ \\ a Jurusan Teknik Sipil, Fakultas Teknik Universitas Tadulako, Jl. Soekarno-Hatta Km 9, Palu 94118, Indonesia \\ ${ }^{b}$ Alumni Jurusan Teknik Sipil, Fakultas Teknik Universitas Tadulako, Jl. Soekarno-Hatta Km 9, Palu 94118, Indonesia \\ ${ }^{*}$ Corresponding author's e-mail: a.asnudin@gmail.com
}

Received: 23 July 2021; revised: 19 August 2021; accepted: 24 August 2021

\begin{abstract}
One effort to empower the implementation of construction projects in order to maintain the quality of the final work is the application of competency standards for workers who hold a strategic position in determining the quality of the final building, in this case plaster workers. The aims of this research was to know the application of plasterer competency standards based on the Indonesian National Work Competency Standards (SKKNI) on building projects in Palu City. This research was conducted on plasterers of buildings in the city of Palu. The research method used was literature study, the primary data collection was done by distributing the questionnaires. The selected respondents were plasterers. Data were processed by using descriptive statistical methods and using the Relative Rank Index (RRI). The results showed that the application of plasterers' work competency standards based on SKKNI was around $80 \%$ to $90 \%$ which had been well implemented, namely, carrying out Preparation of Plastering Work, Carrying Out Plaster Mixing Mixes, Carrying Plaster Work. In addition, around $20 \%$ to $30 \%$ have not been well implemented, namely, the use of PPE and WSE, Making Job Reports.
\end{abstract}

Keywords: plasterers, competence, SKKNI.

\begin{abstract}
Abstrak: Salah satu upaya untuk memberdayakan pelaksanaan proyek konstruksi demi menjaga mutu hasil akhir pekerjaan adalah berupa penerapan standar kompetensi bagi tenaga kerja yang memegang posisi strategis pada penentuan mutu hasil akhir bangunan, dalam hal ini adalah tenaga kerja tukang plester. Penelitian ini bertujuan untuk mengetahui penerapan standar kompetensi tukang plester berdasarkan Standar Kompetensi Kerja Nasional Indonesia (SKKNI) terhadap proyek bangunan gedung di Kota Palu. Penelitian ini dilakukan terhadap tukang plester bangunan gedung di Kota Palu. Metode Penelitian yang digunakan adalah studi literature, pengumpulan data primer dilakukan dengan cara penyebaran kuesioner. Responden yang dipilih adalah tukang plester. Data diolah dengan menggunakan metode statistik deskriptif dengan menggunakan Relative Rank Index (RRI). Hasil penelitian menunjukkan bahwa penerapan standar kompeteni kerja tukang plester berdasarkan SKKNI adalah sekitar 80\% sampai dengan 90\% telah diterapkan dengan baik yaitu, Melaksanakan Persiapan Pekerjaan Plesteran, Melaksanakan Pencampuran Adukan Plester, Melaksanakan Pekerjaan Plesteran. Selain itu sekitar 20\% sampai dengan 30\% belum diterapkan dengan baik yaitu, Penggunaan APD dan APK, Membuat Laporan Pekerjaan.
\end{abstract}

Kata kunci: tukang plester, kompetensi, SKKNI.

\section{Pendahuluan}

Sesuai Undang-Undang Nomor 2 Tahun 2017 tentang Jasa Konstruksi beserta peraturan pelaksanaannya menyatakan bahwa setiap tenaga kerja konstruksi yang bekerja di bidang jasa konstruksi wajib memiliki sertifikat kompetensi kerja [1]. Dalam SKKNI dijelaskan bahwa keharusan memiliki sertifikat kompetensi mencerminkan adanya tuntutan kualitas tenaga kerja yang kompeten. Direktur Jenderal Bina Konstruksi Kementerian Pekerjaan Umum dan Perumahan Rakyat (PUPR) Syarif Burhanuddin mengungkapkan, jumlah tenaga kerja konstruksi di Indonesia sebanyak 8,1 juta orang. Namun, tidak seluruh tenaga kerja konstruksi tersebut memiliki sertifikat. Bahkan, yang tercatat bersersertifikat pun hanya 720.000 orang [2]. Dari pernyataan tersebut masih banyak tenaga kerja yang belum memiliki sertifikat kompetensi.

Oleh karena itu, untuk meningkatkan mutu kerja, maka penerapan standar kompetensi kerja bagi tenaga kerja dapat dijalankan dengan baik agar pelaksanaan proyek konstruksi dapat berjalan dengan lancar dan dengan hasil yang memuaskan [4-6]. Hal inilah yang mendasari penelitian ini untuk mengevaluasi kompetensi kerja tukang, khususnya tukang plester yang menangani proyek gedung di Kota Palu berdasarkan pada Standar Kompetensi Kerja Nasional Indonesia (SKKNI).

Tenaga kerja konstruksi yang paling bawah yang biasa disebut dengan tukang (construction craff) merupakan tenaga kerja yang paling terdepan yang terlibat dan berhadapan langsung dengan pelaksanaan suatu pekerjaan konstruksi. Sebagai tenaga kerja yang paling terdepan tentu saja tukang sebaiknya memiliki spesialisasi dan kompetensi pada bidang tertentu dan bersertifikat [7-9].

Menurut Undang-Undang Nomor 2 Tahun 2017 tentang jasa konstruksi, Pasal 1, Jasa Konstruksi adalah layanan jasa konsultansi konstruksi dan/atau pekerjaan konstruksi. Penyedia Jasa adalah pemberi layanan Jasa Konstruksi. Mengingat tenaga kerja konstruksi atau tukang merupakan bagian dari pelaksana konstruksi, maka sebaiknya memiliki kemampuan dan kompetensi pada bidang tertentu serta bersertifikat.

Menurut kamus besar bahasa Indonesia kompetensi artinya cekatan, lekas (bekerja, mengerti) cepat dan mahir (melakukan sesuatu). Kompetensi menurut Lembaga Pengembangan Jasa Konstruksi Nasional (LPJK) adalah kemampuan orang perseorangan untuk mengerjakan suatu tugas dan pekerjaan sesuai dengan persyaratan yang dilandasi oleh pengetahuan, kecekatan, dan sikap kerja. 
Kopetensi kerja menurut UU No. 13 tahun 2003 adalah kemampuan kerja setiap individu yang mencakup aspek pengetahuan, ketrampilan, dan sikap kerja yang sesuai dengan standar yang ditetapkan. Berdasarkan pengertian kompetensi tersebut di atas, terlihat bahwa kompetensi adalah kemampuan setiap orang dalam melakukan pekerjaan atau tugas berdasarkan pengetahuan, keterampilan dan sikap kerja yang dimiliki [10].

SKKNI merupakan rumusan kemampuan kerja yang mencakup aspek Pengetahuan (knowledge), Keterampilan dan/atau Keahlian (skills) serta Sikap kerja (attitude) yang relevan dengan pelaksanaan tugas dan syarat jabatan yang ditetapkan sesuai dengan ketentuan peraturan perundangundangan yang berlaku. Standar kompetensi kerja merupakan ukuran kemampuan kerja seseorang yang dapat terobservasi dan mencakup atas pengetahuan, keterampilan dan sikap kerja seseorang dalam menyelesaikan suatu fungsi tugas atau pekerjaan sesuai dengan persyaratan pekerjaan yang ditetapkan. Hal ini mengacu pada SKKNI Nomor 307 Tahun 2016 [11].

\section{Metode Penelitian}

Metode yang digunakan dalam penelitian ini adalah penelitian deskriptif. Penelitian deskriptif adalah penelitian yang berusaha mendeskripsikan suatu gejala, peristiwa, kejadian yang terjadi pada saat sekarang [12]. Jenis penelitian yang dipergunakan dalam penelitian ini adalah penelitian kualitatif. Penelitian kualitatif adalah suatu pendekatan dalam melakukan penelitian yang berorientasi pada fenomena atau gejala yang bersifat alami [13]. Penelitian kualitatif bertujuan untuk mendapatkan pemahaman yang mendalam tentang suatu fenomena yang akan diteliti.

\subsection{Objek Penelitian}

Objek penelitian ini adalah tenaga kerja tukang plester. Pengambilan data dilakukan pada tukang plester yang menangani proyek bangunan gedung di Kota Palu.

\subsection{Lokasi Penelitian}

Penelitian dilakukan di sekitar Kota Palu provinsi Sulawesi Tengah yaitu pada royek konstruksi khususnya bangunan gedung yang ada di Kota Palu

\subsection{Teknik Pengumpulan Data}

Proses pengumpulan data ini dimaksudkan untuk memudahkan dalam memperoleh data yang dibutuhkan guna menunjang tugas akhir ini. Data yang diambil berupa data primer dan data sekunder. Instrument pengumpulan data yang digunakan untuk pengumpulan data primer adalah kuesioner (angket). Sedangkan data sekunder diperoleh dari data pendukung berupa informasi dan juga melalui studi kepustakaan untuk mendukung analisis dan pembahasan yang berkaitan dengan penelitian ini.

Adapun cara mendapatkannya yaitu dengan wawancara langsung dengan tenaga kerja tukang plester dan memberikan kuesioner yang menyangkut penelitian. Pada penelitian ini kuesioner digunakan untuk mengumpulkan data yang berkenaan kemampuan kompetensi kerja tukang plester.

\section{Hasil dan Pembahasan}

\subsection{Profil Tenaga Kerja Tukang Plester}

Usia responden terdapat $7 \%$ yang memiliki usia di bawah 25 tahun, 60\% yang memiliki usia di antara $25-40$ tahun, 33\% yang memiliki usia di atas 40 tahun. Diketahui bahwa jumlah responden didominasi usia antara $25-40$ tahun yaitu $60 \%$. Pada rentang usia ini pekerja memiliki fisik atau jasmani kuat dan sehat serta mampu bekerja dengan baik. Pekerja akan berusaha semaksimal memberikan yang terbaik berdasarkan pengetahuan dan pengalaman-pengalaman yang dimiliki.

Pengalaman kerja responden terdapat $7 \%$ yang memiliki pengalaman kerja $\leq 3$ tahun, $36 \%$ pengalaman kerja $4-10$ tahun, $57 \%$ pengalaman kerja $\geq 11$ tahun. Diketahui bahwa jumlah responden didominasi pengalaman kerja $\geq 11$ tahun yaitu $57 \%$, Hal ini menujukkan bahwa pekerja memiliki pengalaman kerja yang baik dibidang konstruksi. Pengalaman kerja ini sangat dibutuhkan agar pekerja bisa bekerja dan belajar dari proyek-proyek sebelumnya, karena setiap proyek mempunyai karakteristik berbeda-beda. Kepemilikan sertifikat responden $65 \%$ belum memiliki Sertifikat, 35\% yang sudah memiliki sertifikat. Diagram diatas menunjukkan bahwa tenaga kerja tukang plester masih banyak yang belum memiliki sertifikat.

\subsection{Hasil Analisis Reability Cronbach's Alpha}

Untuk menghitung reabilitas dilakukan dengan menggunakan Koefisien Cronbach Alpha, diukur berdasarkan skala Cronbach Alpha dari 0 sampai 1. Tabel 1 menunjukkan bahwa variabel mempunyai koefisien alpha 0,997 yaitu di atas indeks minimum yaitu sebesar 0,60 atau dapat dikatakan semua indikator variabel dari kuesioner adalah reliabel.

Tabel 1. Hasil uji reliabilitas

\begin{tabular}{cc}
\hline \multicolumn{2}{c}{ Reliability Statistics } \\
\hline Cronbach's Alpha & Nof Items \\
\hline .997 & 30 \\
\hline
\end{tabular}

\subsection{Hasil Analisa Likert}

Data yang diperoleh dari hasil penelitian diolah dengan menggunakan Skala Likert untuk tingkat penilaian terhadap nilai penerapan kompetensi kerja yang dimiliki oleh tenaga kerja tukang plester pada pekerjan bangunan gedung dengan menggunakan program Microsoft Excel (Tabel 2).

Tabel 2. Analisa kompetensi kerja tukang plester pekerjaan gedung di Kota Palu

\begin{tabular}{llc}
\hline No. & \multicolumn{1}{c}{ Daftar Pertanyaan } & $\begin{array}{c}\text { Skala } \\
\text { Likert }\end{array}$ \\
\hline I & Penggunaan APD dan APK & \\
\hline I.1 & $\begin{array}{l}\text { APD dan APK yang dibutuhkan } \\
\text { diidentifikasi sesuai dengan } \\
\text { kebutuhan }\end{array}$ & $22,67 \%$ \\
\hline I.2 & $\begin{array}{l}\text { APK dan APD dipakai sesuai } \\
\text { prosedur }\end{array}$ & $26,67 \%$ \\
\hline I.3 & $\begin{array}{l}\text { APK dan APD diperiksa sesuai } \\
\text { dengan standar }\end{array}$ & $22,67 \%$ \\
\hline \multicolumn{2}{c}{ Rata-rata } \\
\hline
\end{tabular}


REKonSTRUKSI TADULAKO: Civil Engineering Journal on Research and Development, Vol. 2(2), September 2021

Lanjutan Tabel 2. Analisa kompetensi kerja tukang plester pekerjaan gedung di Kota Palu

\begin{tabular}{|c|c|c|}
\hline No. & Daftar Pertanyaan & $\begin{array}{c}\text { Skala } \\
\text { Likert }\end{array}$ \\
\hline II & $\begin{array}{l}\text { Melaksanakan Persiapan } \\
\text { Pekerjaan Plesteran }\end{array}$ & \\
\hline II.1 & $\begin{array}{l}\text { Tempat menyimpan material } \\
\text { plesteran ditentukan sesuai dengan } \\
\text { persyaratan teknis, keamanan, } \\
\text { Keselamatan dan Kesehatan Kerja } \\
\text { (K3) }\end{array}$ & $78,00 \%$ \\
\hline II. 2 & $\begin{array}{l}\text { Gambar kerja arsitektur dan instruksi } \\
\text { kerja plesteran digunakan sebagai } \\
\text { dasar pelaksanaan pekerjaan plesteran }\end{array}$ & $82,67 \%$ \\
\hline II. 3 & $\begin{array}{l}\text { Gambar denah lokasi pekerjaan } \\
\text { ditentukan sesuai dengan instruksi } \\
\text { kerja }\end{array}$ & $84,00 \%$ \\
\hline II.4 & $\begin{array}{l}\text { Perkakas untuk mengerjakan } \\
\text { plesteran dan acian disiapkan sesuai } \\
\text { kebutuhan }\end{array}$ & $85,33 \%$ \\
\hline II.5 & $\begin{array}{l}\text { Kerusakan alat dan perkakas } \\
\text { pekerjaan plesteran diperiksa dengan } \\
\text { tepat }\end{array}$ & $90,67 \%$ \\
\hline II.6 & $\begin{array}{l}\text { Alat dan perkakas yang sudah rusak } \\
\text { diganti dengan yang siap pakai }\end{array}$ & $88,00 \%$ \\
\hline \multirow[t]{2}{*}{ II.7 } & $\begin{array}{l}\text { Perawatan alat/mesin pencampur } \\
\text { adukan plesteran dilakukan secara } \\
\text { rutin }\end{array}$ & $94,00 \%$ \\
\hline & Rata-rata & $86,10 \%$ \\
\hline III & $\begin{array}{l}\text { Melaksanakan Pencampuran } \\
\text { Adukan Plester }\end{array}$ & \\
\hline III.1 & $\begin{array}{l}\text { Lokasi tempat pencampuran adukan } \\
\text { semen plaster disiapkan sesuai } \\
\text { instruksi kerja }\end{array}$ & $83,33 \%$ \\
\hline III.2 & $\begin{array}{l}\text { Perbandingan campuran material } \\
\text { adukan semen diatur sesuai dengan } \\
\text { instruksi kerja }\end{array}$ & $82,00 \%$ \\
\hline III.3 & $\begin{array}{l}\text { Tempat kerja dibersihkan sesuai } \\
\text { dengan prosedur. }\end{array}$ & $80,67 \%$ \\
\hline \multirow[t]{2}{*}{ III.4 } & $\begin{array}{l}\text { Perbandingan campuran material } \\
\text { pasta semen diatur sesuai instruksi } \\
\text { kerja }\end{array}$ & $84,00 \%$ \\
\hline & Rata-rata & $82,50 \%$ \\
\hline IV & Melaksanakan Pekerjaan Plesteran & \\
\hline IV.1 & $\begin{array}{l}\text { Pekerjaan pematokan } \\
\text { (profil/kepalaan) permukaan dinding } \\
\text { yang akan diplester dipasang sesuai } \\
\text { dengan gambar kerja dan instruksi } \\
\text { kerja }\end{array}$ & $81,33 \%$ \\
\hline IV.2 & $\begin{array}{l}\text { Kepalaan penyangga permukaan } \\
\text { dinding dipasang pada posisi tegak } \\
\text { lurus dengan permukaan yang rata } \\
\text { sesuai dengan gambar kerja dan } \\
\text { instruksi kerja. }\end{array}$ & $78,67 \%$ \\
\hline IV.3 & $\begin{array}{l}\text { Pekerjaan plesteran dinding rata } \\
\text { dilaksanakan dengan acuan } \\
\text { penyangga permukaan. }\end{array}$ & $90,00 \%$ \\
\hline IV.4 & $\begin{array}{l}\text { Kerapihan dan kebersihan tempat } \\
\text { kerja dipelihara secara rutin }\end{array}$ & $82,00 \%$ \\
\hline
\end{tabular}

Lanjutan Tabel 2. Analisa kompetensi kerja tukang plester pekerjaan gedung di Kota Palu

\begin{tabular}{llc}
\hline No. & \multicolumn{1}{c}{ Daftar Pertanyaan } & $\begin{array}{c}\text { Skala } \\
\text { Likert }\end{array}$ \\
\hline IV.5 & $\begin{array}{l}\text { Pekerjaan plesteran dinding rata } \\
\text { diperikasai kesesuaiannya dengan } \\
\text { gambar kerja dan instruksi kerja }\end{array}$ & $68,67 \%$ \\
\hline \multicolumn{3}{c}{ Rata-rata } \\
\hline V & Membuat Laporan Pekerjaan \\
\hline V.1 & $\begin{array}{l}\text { Laporan hasil inspeksi pekerjaan } \\
\text { plesteran dinding rata dibuat sesuai } \\
\text { instruksi kerja dan borang-borang } \\
\text { yang tersedia, untuk disampaikan } \\
\text { kepada pihak terkait }\end{array}$ & \multicolumn{1}{c}{ Rata-rata } \\
\hline \multicolumn{3}{c}{$20,00 \%$} \\
\hline
\end{tabular}

Tabel 3. Hasil rangking 10 (sepuluh) peringkat tertinggi kompetensi kerja tukang plester pekerjaan gedung di Kota Palu

\begin{tabular}{|c|c|c|c|}
\hline No & Daftar Pertanyaan & $\begin{array}{c}\text { Skala } \\
\text { Likert }\end{array}$ & Rank \\
\hline II.7 & $\begin{array}{l}\text { Perawatan alat } / \text { mesin } \\
\text { pencampur adukan } \\
\text { plesteran dilakukan secara } \\
\text { rutin }\end{array}$ & $94,0 \%$ & 1 \\
\hline II.5 & $\begin{array}{l}\text { Kerusakan alat dan } \\
\text { perkakas pekerjaan } \\
\text { plesteran diperiksa dengan } \\
\text { tepat }\end{array}$ & $90,7 \%$ & 2 \\
\hline IV.4 & $\begin{array}{l}\text { Pekerjaan plesteran dinding } \\
\text { rata dilaksanakan dengan } \\
\text { acuan penyangga } \\
\text { permukaan }\end{array}$ & $90,0 \%$ & 3 \\
\hline II.6 & $\begin{array}{l}\text { Alat dan perkakas yang } \\
\text { sudah rusak diganti dengan } \\
\text { yang siap pakai }\end{array}$ & $88,0 \%$ & 4 \\
\hline II.4 & $\begin{array}{l}\text { Perkakas untuk } \\
\text { mengerjakan plesteran dan } \\
\text { acian disiapkan sesuai } \\
\text { kebutuhan }\end{array}$ & $85,3 \%$ & 5 \\
\hline III. 2 & $\begin{array}{l}\text { Perbandingan campuran } \\
\text { material pasta semen diatur } \\
\text { sesuai instruksi kerja }\end{array}$ & $84,0 \%$ & 6 \\
\hline II. 3 & $\begin{array}{l}\text { Gambar denah lokasi } \\
\text { pekerjaan ditentukan sesuai } \\
\text { dengan instruksi kerja }\end{array}$ & $84,0 \%$ & 7 \\
\hline III.1 & $\begin{array}{l}\text { Lokasi tempat } \\
\text { pencampuran adukan } \\
\text { semen plaster disiapkan } \\
\text { sesuai instruksi kerja }\end{array}$ & $83,3 \%$ & 8 \\
\hline II. 2 & $\begin{array}{l}\text { Gambar kerja arsitektur } \\
\text { dan instruksi kerja } \\
\text { plesteran digunakan } \\
\text { sebagai dasar pelaksanaan } \\
\text { pekerjaan plesteran }\end{array}$ & $82,7 \%$ & 9 \\
\hline IV.3 & $\begin{array}{l}\text { Kerapihan dan kebersihan } \\
\text { tempat kerja dipelihara } \\
\text { secara rutin }\end{array}$ & $82,0 \%$ & 10 \\
\hline
\end{tabular}


Berdasarkan hasil penelitian pada Tabel 3 mengenai kompetensi kerja tukang plester di Kota Palu dengan hasil pengolahan data menggunakan Relative Rank Index (RRI), diperoleh hasil ranking sebagai berikut:

1) Perawatan alat/mesin pencampur adukan plesteran dilakukan secara rutin

Berdasarkan hasil pengolahan data pada Tabel 3 diperoleh hasil bahwa tukang plester dalam melakukan Perawatan alat/mesin pencampur adukan plesteran dilakukan secara rutin sebesar 94\% serta hasil RRI 0,940 menduduki peringkat pertama. Mesin Molen merupakan mesin yang digunakan untuk mencampur material batu kerikil, pasir dan semen guna mendapat hasil pencampuran yang merata. Dengan menggunakan mesin pencampur adukan mendapatkan hasil campuran yang merata. Dengan menggunakan mesin pencampur pekerjaan yang dijalankan bisa berjalan lancar. Penggunaan mesin ini juga harus dirawat agar tetap terjaga agar tidak cepat rusak dan tetap dalam kondsi baik beroprasi.

2) Kerusakan alat dan perkakas pekerjaan plesteran diperiksa dengan tepat

Berdasarkan hasil pengolahan data pada Tabel 3 diperoleh hasil bahwa tukang plester dalam hal Kerusakan alat dan perkakas pekerjaan plesteran diperiksa dengan tepat sebesar 90,7\% serta hasil RRI 0,907 menduduki peringkat kedua. Kerusakan alat dan perkakas harus di periksa dengan tepat agar dapat digunakan dengan baik. Salah satu sikap profesional seorang tukang adalah selalu memelihara dan merawat alat-alat yang dimilikinya sehingga alat dalam kondisi selalu siap pakai melalui tindakan-tindakan sesuai dengan situasi dan kondisi yang ada.

3) Pekerjaan plesteran dinding rata dilaksanakan dengan acuan penyangga permukaan

Berdasarkan hasil pengolahan data pada Tabel 3 diperoleh hasil bahwa tukang plester dalam hal Pekerjaan plesteran dinding rata dilaksanakan dengan acuan penyangga permukaan sebesar $90 \%$ serta hasil RRI 0,900 menduduki peringkat ketiga. Pekerjaan plesteran harus dilaksanakan berdasarkan acuan penyangga permukaan yang telah dibuat untuk kelurusan hasil plesteran.

4) Alat dan perkakas yang sudah rusak diganti dengan yang siap pakai

Berdasarkan hasil pengolahan data pada Tabel 3 diperoleh hasil bahwa tukang plester dalam hal Alat dan perkakas yang sudah rusak diganti dengan yang siap pakai sebesar $88 \%$ serta hasil RRI 0,880 menduduki peringkat keempat. Alat dan perkakas yang sudah rusak apabila sudah tidak bisa diperbaiki sebaiknya segera diganti dengan yang siap pakai agar tidak menghambat kelancaran pekerjaan.

5) Perkakas untuk mengerjakan plesteran dan acian disiapkan sesuai kebutuhan

Berdasarkan hasil pengolahan data pada Tabel 3 diperoleh hasil bahwa tukang plester dalam hal Perkakas untuk mengerjakan plesteran dan acian disiapkan sesuai kebutuhan sebesar 85,3\% serta hasil RRI 0,853 menduduki peringkat kelima. Kompetensi memilih alat sangat penting bagi seorang tukang plester karena seorang tukang akan dapat menentukan alat yang harus digunakan sesuai dengan jenis atau tahapan pekerjaan yang akan dilakukan.

6) Perbandingan campuran material pasta semen diatur sesuai instruksi kerja.

Berdasarkan hasil pengolahan data pada Tabel 3 diperoleh hasil bahwa tukang plester dalam hal Perbandingan campuran material pasta semen diatur sesuai instruksi kerja sebesar $84 \%$ serta hasil RRI 0,840 menduduki peringkat keenam. Dalam membuat adukan seorang tukang plester harus dapat mengetahui jenis adukan untuk plesteran dan acian, mutu adukan, cara mencampur adukan dengan alat tangan, serta cara mencampur adukan dengan mesin. Serta melakukan pekerjaan berdasarkan instruksi kerja agar proses pelaksanaannya sesuai dengan persyaratan, baik metode kerja dan spesifikasi teknis.

7) Gambar denah lokasi pekerjaan ditentukan sesuai dengan instruksi kerja

Berdasarkan hasil pengolahan data pada Tabel 3 diperoleh hasil bahwa tukang plester dalam hal Gambar denah lokasi pekerjaan ditentukan sesuai dengan instruksi kerja sebesar 84\% serta hasil RRI 0,840 menduduki peringkat ketujuh. Denah lokasi pekerjaan ditentukan sesuai instruksi kerja untuk mengetahui tempat dan dan letak dari pekerjaan

8) Lokasi tempat pencampuran adukan semen plaster disiapkan sesuai instruksi kerja

Berdasarkan hasil pengolahan data pada Tabel 3 diperoleh hasil bahwa tukang plester dalam hal Lokasi tempat pencampuran adukan semen plaster disiapkan sesuai instruksi kerja sebesar 83,3\% serta hasil RRI 0,833 menduduki peringkat kedelapan. Lokasi tempat pencampuran adukan diatur sedemikian rupa serta sesuai instruksi kerja agar tidak mengganggu kelancaran pekerjaan. Sehingga memudahkan bagi pengawas serta menjamin tercapainya mutu adukan yang baik dan terlindung.

9) Gambar kerja arsitektur dan instruksi kerja plesteran digunakan sebagai dasar pelaksanaan pekerjaan plesteran

Berdasarkan hasil pengolahan data pada Tabel 3 diperoleh hasil bahwa tukang plester dalam hal Gambar kerja arsitektur dan instruksi kerja plesteran digunakan sebagai dasar pelaksanaan pekerjaan plesteran sebesar $82,7 \%$ serta hasil RRI 0,827 menduduki peringkat kesembilan. Pekerjaan plesteran sebaiknya dilaksanakan berdasarkan gambar kerja dan instruksi kerja agar proses pelaksanaannya sesuai dengan persyaratan, baik metode kerja, spesifikasi teknis maupun gambar kerja yang ditetapkan. 
10) Kerapihan dan kebersihan tempat kerja dipelihara secara rutin

Berdasarkan hasil pengolahan data pada Tabel 3 diperoleh hasil bahwa tukang plester dalam hal Kerapihan dan kebersihan tempat kerja dipelihara secara rutin sebesar $82 \%$ serta hasil RRI 0,820 menduduki peringkat kesepuluh. Sebagai seorang tenaga kerja tukang tentunya tidak hanya dituntut terampil dalam melakukan pekerjaannya tetapi juga dituntut untuk memiliki sikap kerja yang sesuai dengan prinsip-prinsip keselamatan dan kesehatan kerja. Salah satu sikap kerja profesional yang harus dimiliki ialah selalu menjaga kebersihan lingkungan kerja dengan cara membersihkan lokasi kerja.

Tabel 4. Hasil rangking 4 (empat) peringkat terendah kompetensi kerja tukang plester pekerjaan gedung di Kota Palu

\begin{tabular}{llcc}
\hline No & \multicolumn{1}{c}{ Daftar Pertanyaan } & $\begin{array}{c}\text { Skala } \\
\text { Likert }\end{array}$ & Rank \\
\hline V.1 & $\begin{array}{l}\text { Laporan hasil inspeksi } \\
\text { pekerjaan plesteran dinding }\end{array}$ & $20,0 \%$ & 1 \\
& $\begin{array}{l}\text { rata dibuat sesuai instruksi } \\
\text { kerja dan borang-borang yang }\end{array}$ & & \\
& tersedia, untuk disampaikan & & \\
& kepada pihak terkait & & \\
\hline I.1 & APD dan APK yang & 22,67 & 2 \\
& dibutuhkan diidentifikasi & $\%$ & \\
& sesuai dengan kebutuhan & & \\
\hline I.2 & APD dan APK diperiksa & 22,67 & 3 \\
& sesuai dengan standar & $\%$ & \\
\hline I.3 & APD dan APK dipakai sesuai & 26,67 & 4 \\
& prosedur & $\%$ & \\
\hline
\end{tabular}

Dari hasil penelitian pada Tabel 4 mengenai kompetensi kerja tukang plester di Kota Palu dengan hasil pengolahan data menggunakan Relative Rank Index (RRI), diperoleh hasil ranking sebagai berikut:

1) Laporan hasil inspeksi pekerjaan plesteran dinding rata dibuat sesuai instruksi kerja dan borang-borang yang tersedia, untuk disampaikan kepada pihak terkait

Berdasarkan hasil pengolahan data pada Tabel 4 diperoleh hasil bahwa tukang plester dalam hal Laporan hasil inspeksi pekerjaan plesteran dinding rata dibuat sesuai instruksi kerja dan borang-borang yang tersedia, untuk disampaikan kepada pihak terkait sebesar 20,0\% serta hasil RRI 0,20 menduduki peringkat pertama. Tukang seharusnya memiliki dan menguasai kemampuan tidak hanya mengerjakan pekerjaan plesteran dan acian saja, menggunakan alat, ataupun membuat adukan plester saja, tukang juga seharusnya dapat membuat laporan kegiatan sederhana mengenai volume pekerjaan dan laporan hasil pemeriksaan pekerjaan [14]. Oleh karena itu, hal-hal tersebut termasuk dalam upaya menciptakan tukang yang menguasai kompetensi sesuai dengan kebutuhan di lapangan.

2) APD dan APK yang dibutuhkan diidentifikasi sesuai dengan kebutuhan
Berdasarkan hasil pengolahan data pada Tabel 4. diperoleh hasil bahwa tukang plester dalam hal APD dan APK yang dibutuhkan diidentifikasi sesuai dengan kebutuhan sebesar 22,67\% serta hasil RRI 0,227 menduduki peringkat kedua. Dalam materi pelatihan K3L tukang bangunan gedung 2011, Alat Pelindung Diri (APD) dan Alat Pengaman Kerja (APK) adalah kelengkapan yang wajib digunakan saat bekerja, Pemilihan jenis APD dan APK tergantung pada jenis pekerjaannya, risiko yang mungkin terjadi, pemilihan APD bertujuan untuk melindungi bagian-bagian tubuh pekerja yang berisiko luka atau terdampak penyakit yang diakibatkan oleh adanya kontak dengan bahaya di tempat kerja. Sedangkan Pemilihan APK bertujuan untuk melindungi bagian-bagian tubuh pekerja yang berisiko terjatuh dari lokasi kerja di ketinggian. Oleh karna itu pemilihan jenis APK dan APD sangat penting bagi tenaga kerja tukang sesuai dengan jenis pekerjaan serta bahaya dan resiko kerja yang mungkin terjadi.

3) APD dan APK diperiksa sesuai dengan standar

Berdasarkan hasil pengolahan data pada Tabel 4 diperoleh hasil bahwa tukang plester dalam hal APK dan APD diperiksa sesuai dengan standar sebesar 22,67\% serta hasil RRI 0,227 menduduki peringkat Ketiga. Penggunaan APD dan APK yang berstandar sangat diperlukan, karena banyak kasus di mana pekerja yang sudah menggunakan APD dan APK masih bisa terkena kecelakaan akibat alat yang dipakainya tidak memenuhi standar. Pemeriksaan kondisi APD dan APK dimaksudkan agar para tukang menggunakan APD dan APK yang memenuhi standar yang ditetapkan sesuai jenis pekerjaannya.

Berdasarkan materi pelatihan $\mathrm{K} 3 \mathrm{~L}$ tukang bangunan gedung 2011, Adapun prosedur pemeriksaan APD dan APK yang dapat dilakukan yaitu: a. Periksa jenis APD kelengkapan dan kebersihannya serta kemungkinan adanya kerusakan hingga tidak layak pakai; b. Pastikan APD yang digunakan aman untuk keselamatan, c. jika tidak sesuai maka perlu diganti dengan yang baru.

4) APD dan APK dipakai sesuai prosedur

Berdasarkan hasil pengolahan data pada Tabel 4 diperoleh hasil bahwa tukang plester dalam hal APK dan APD dipakai sesuai prosedur sebesar $26,67 \%$ serta hasil RRI 0,267 menduduki peringkat keempat. Dalam materi pelatihan K3L tukang bangunan gedung 2011, Alat Pelindung Diri (APD) dan Alat Pengaman Kerja (APK) adalah kelengkapan yang wajib digunakan saat bekerja sesuai bahaya dan risiko kerja untuk menjaga keselamatan pekerja itu sendiri dan orang di sekelilingnya. APD dan APK adalah suatu alat yang mempunyai kemampuan untuk melindungi seseorang dalam pekerjaan yang fungsinya mengisolasi tubuh tenaga kerja dari bahaya di tempat kerja.

APD dan APK akan berfungsi dengan sempurna apabila telah sesuai dengan standar yang ditentukan dan dipakai secara baik dan benar. Hal-hal yang perlu diperhatikan yaitu : a. Sediakanlah APD dan APK yang sudah teruji dan telah memiliki SNI atau standar Internasional 
lainnya yang diakui; b. Pakailah APD dan APK yang seuai dengan jenis pekerjaan walaupun pekerjaan tersebut hanya memerlukan waktu yang singkat; c. APD harus dipakai dengan tepat dan benar; d. Jadikanlah kebiasaan memakai APD menjadi budaya; Ketidaknyamanan dalam memakai APD jangan dijadikan alasan untuk menolak memakainya; e. APD tidak boleh diubah-ubah pemakainya, kalau memang terasa tidak nyaman dipakai harus dilaporkan kepada atasan atau pemberi kewajiban pemakaian alat tersebut; f. APD dijaga agar tetap berfungsi dengan baik.

\subsection{Hasil Analisa Korelasi Spearman's Rank}

Untuk mengetahui seberpa besar korelasi antara kriteria unjuk kerja yang satu dengan kriteria unjuk kerja yang lainnya maka digunakan program Statistical Product and Service Solution (SPSS) untuk melakukan korelasi berdasarkan metode spearman rho. Hasil korelasi antara beberapa kriteria unjuk kerja dapat di lihat pada Tabel 5 .

Tabel 5. Korelasi signifikansi pada level 0,01

\begin{tabular}{|c|c|c|c|c|}
\hline No & Simbol & Korelasi & $\begin{array}{c}\text { Nilai } \\
\text { Kore- } \\
\text { lasi }\end{array}$ & Rank \\
\hline 1 & II. 2 & $\begin{array}{l}\text { Gambar kerja arsitektur } \\
\text { dan instruksi kerja } \\
\text { plesteran digunakan } \\
\text { sebagai dasar } \\
\text { pelaksanaan pekerjaan } \\
\text { plesteran }\end{array}$ & \multirow[t]{2}{*}{1,000} & \multirow[t]{2}{*}{1} \\
\hline & I. 1 & $\begin{array}{l}\text { APD dan APK yang } \\
\text { dibutuhkan diidentifikasi } \\
\text { sesuai dengan kebutuhan }\end{array}$ & & \\
\hline 2 & II. 2 & $\begin{array}{l}\text { Gambar kerja arsitektur } \\
\text { dan instruksi kerja } \\
\text { plesteran digunakan } \\
\text { sebagai dasar } \\
\text { pelaksanaan pekerjaan } \\
\text { plesteran }\end{array}$ & \multirow[t]{2}{*}{0,712} & \multirow[t]{2}{*}{2} \\
\hline & I.3 & $\begin{array}{l}\text { APD dan APK dipakai } \\
\text { sesuai prosedur }\end{array}$ & & \\
\hline \multirow[t]{2}{*}{3} & I. 3 & $\begin{array}{l}\text { APD dan APK dipakai } \\
\text { sesuai prosedur }\end{array}$ & \multirow[b]{2}{*}{0,712} & \multirow[b]{2}{*}{3} \\
\hline & I.1 & $\begin{array}{l}\text { APD dan APK yang } \\
\text { dibutuhkan diidentifikasi } \\
\text { sesuai dengan kebutuhan }\end{array}$ & & \\
\hline \multirow[t]{2}{*}{4} & II. 2 & $\begin{array}{l}\text { Gambar kerja arsitektur } \\
\text { dan instruksi kerja } \\
\text { plesteran digunakan } \\
\text { sebagai dasar } \\
\text { pelaksanaan pekerjaan } \\
\text { plesteran }\end{array}$ & \multirow[t]{2}{*}{0,703} & \multirow[t]{2}{*}{4} \\
\hline & $\mathrm{I} .2$ & $\begin{array}{l}\text { APD dan APK diperiksa } \\
\text { sesuai dengan standar }\end{array}$ & & \\
\hline \multirow[t]{2}{*}{5} & I. 3 & $\begin{array}{l}\text { APD dan APK dipakai } \\
\text { sesuai prosedur }\end{array}$ & \multirow{2}{*}{0,703} & \multirow{2}{*}{5} \\
\hline & I. 2 & $\begin{array}{l}\text { APD dan APK diperiksa } \\
\text { sesuai dengan standar }\end{array}$ & & \\
\hline
\end{tabular}

Lanjutan Tabel 5. Korelasi signifikansi pada level 0,01

\begin{tabular}{ccccc}
\hline No & Simbol & Korelasi & $\begin{array}{c}\text { Nilai } \\
\text { Kore- } \\
\text { lasi }\end{array}$ & Rank \\
\hline 6 & I.2 & $\begin{array}{c}\text { APD dan APK diperiksa } \\
\text { sesuai dengan standar }\end{array}$ & \\
\cline { 2 - 3 } & I.1 & $\begin{array}{l}\text { APD dan APK yang } \\
\text { dibutuhkan diidentifikasi } \\
\text { sesuai dengan kebutuhan }\end{array}$ & \\
\hline
\end{tabular}

Tabel 6. Korelasi signifikansi pada level 0,05

\begin{tabular}{|c|c|c|c|c|}
\hline No & Simbol & Korelasi & $\begin{array}{c}\text { Nilai } \\
\text { Kore- } \\
\text { lasi }\end{array}$ & Rank \\
\hline 1 & III. 2 & $\begin{array}{l}\text { Perbandingan campuran } \\
\text { material pasta semen } \\
\text { diatur sesuai instruksi } \\
\text { kerja. }\end{array}$ & \multirow{2}{*}{0,447} & \multirow{2}{*}{1} \\
\hline & III.1 & $\begin{array}{l}\text { Lokasi tempat } \\
\text { pencampuran adukan } \\
\text { semen plaster disiapkan } \\
\text { sesuai instruksi kerja }\end{array}$ & & \\
\hline \multirow[t]{2}{*}{2} & II. 3 & $\begin{array}{l}\text { Gambar denah lokasi } \\
\text { pekerjaan ditentukan } \\
\text { sesuai dengan instruksi } \\
\text { kerja }\end{array}$ & \multirow{2}{*}{0,382} & \multirow{2}{*}{2} \\
\hline & III.1 & $\begin{array}{l}\text { Lokasi tempat } \\
\text { pencampuran adukan } \\
\text { semen plaster disiapkan } \\
\text { sesuai instruksi kerja }\end{array}$ & & \\
\hline
\end{tabular}

Dari hasil korelasi kompetensi kerja tukang plester 10 (sepuluh) peringkat tertinggi dan 4 (empat) peringkat terendah kriteria unjuk kerja terdapat beberapa kriteria unjuk kerja yang mempunyai hubungan yang sangat signifikan pada level 0,01 dapat dilihat pada Tabel 5 yaitu gambar kerja arsitektur dan instruksi kerja plesteran digunakan sebagai dasar pelaksanaan pekerjaan plesteran dengan APD dan APK yang dibutuhkan diidentifikasi sesuai dengan kebutuhan dengan nilai korelasi 1,000 dan juga Gambar kerja arsitektur dan instruksi kerja plesteran digunakan sebagai dasar pelaksanaan pekerjaan plesteran dengan APD dan APK dipakai sesuai prosedur dengan nilai korelasi 0,712. Hal ini menunjukkan bahwa Gambar kerja dan instruksi kerja plesteran digunakan sebagai dasar pelaksanaan pekerjaan dapat menjadi acuan dalam menentukan jenis APD dan APK yang dibutuhkan diidentifikasi sesuai dengan kebutuhan. Instruksi kerja merupakan prosedur kerja yang disusun secara berurutan untuk memandu pelaksanaan dan mempermudah suatu pekerjaan yang berhubungan dengan alat kerja, bahaya mekanik, bahaya kimia, bahaya fisik dan bahaya biologis. Instruksi kerja digunakan untuk mengendalikan lingkungan kerja, alat pelindung diri maupun prosedur kerja. Instruksi Kerja merupakan standar penerapan K3 dari pihak perusahaan untuk semua karyawan supaya meminimalkan kegagalan, kesalahan, dan kelalaian dalam bekerja [15].

Menurut Henrich (2015) bahwa Kecelakaan kerja 80\% disebabkan akibat perilaku kerja yang tidak aman dan $20 \%$ kondisi kerja tidak aman dan faktor lainnya. Seperti tidak 
memakai APD, tidak mengikuti prosedur kerja, tidak mengikuti peraturan keselamatan kerja dan bekerja tidak hati-hati [10].

Berdasarkan materi pelatihan K3L tukang bangunan gedung 2011, Pemilihan APD dan APK tergantung pada jenis pekerjaannya dan resiko yang mungkin terjadi. Adapun APD dan APK yang akan digunakan diperiksa sesuai dengan standard agar para pemakai menggunakan APD dan APK yang memenuhi standar yang ditetapkan sesuai jenis pekerjaannya serta APD dan APK akan berfungsi dengan sempurna apabila telah sesuai dengan standar yang ditentukan dan dipakai secara baik dan benar sesuai dengan prosedur.

Untuk kriteria unjuk kerja yang mempunyai hubungan signifikan pada level 0,05 dapat dilihat pada Tabel 6, yaitu Perbandingan campuran material pasta semen diatur sesuai instruksi kerja dengan Lokasi tempat pencampuran adukan semen plaster disiapkan sesuai instruksi kerja dengan nilai korelasi 0,447 dan juga Gambar denah lokasi pekerjaan ditentukan sesuai dengan instruksi kerja dengan Lokasi tempat pencampuran adukan semen plaster disiapkan sesuai instruksi kerja dengan nilai korelasi 0,382.

Berdasarkan SKKNI 2016, Instruksi kerja adalah dokumen acuan tentang persyaratan teknis pekerjaan plesteran, tentang jenis material, perbandingan campuran, persyaratan pelaksanaan, metode pelaksanaan dan sebagainya, yang harus disiapkan oleh pemberi kerja/atasannya.

Hal ini menunjukkan bahwa pada saat melakukan pekerjaan pencampuran adukan semen, perbandingan campuran material dan penentuan lokasi pekerjaan sudah seharusnya dilakukan sesuai dengan instruksi kerja untuk mengetahui tempat dan dan letak dari pekerjaan serta lokasi tempat pencampuran adukan. Agar tidak mengganggu kelancaran pekerjaan dan dapat menjaga mutu adukan serta proses pelaksanaannya sesuai dengan persyaratan, baik metode kerja dan spesifikasi teknis.

\section{Kesimpulan dan Saran}

\subsection{Kesimpulan}

Hasil penelitian menunjukkan bahwa penerapan standar kompeteni kerja tukang plester berdasarkan SKKNI adalah sebagai berikut:

1) Penerapan standar kompetensi tukang plester sekitar 80\% sampai dengan $90 \%$ telah diterapkan dengan baik yaitu, (1) Melaksanakan Persiapan Pekerjaan Plesteran; (2) Melaksanakan Pencampuran Adukan Plester; (3) Melaksanakan Pekerjaan Plesteran. Selain itu sekitar $20 \%$ sampai dengan $30 \%$ belum diterapkan dengan baik yaitu, (1) Penggunaan APD dan APK; (2) Membuat Laporan Pekerjaan.

2) Dari hasil pengujian korelasi kompetensi kerja tukang plester terdapat kriteria unjuk kerja yang sangat signfikan yaitu, gambar kerja arsitektur dan instruksi kerja plesteran digunakan sebagai dasar pelaksanaan pekerjaan plesteran dengan APD dan APK yang dibutuhkan diidentifikasi sesuai dengan kebutuhan, dengan nilai korelasi 1,000 .
Penggunaan serta pemilihan jenis APD dan APK sebaiknya berdasarkan kebutuhan dan standar oprasional prosedur disesuaikan dengan gambar kerja dan instruksi kerja.

\subsection{Saran}

Berdasarkan hasil penelitian tentang kompetensi kerja tukang plester di Kota Palu maka peneliti memberikan sebagai berikut:

1) Perlunya dilakukan pelatihan secara rutin tentang standard kompetensi kerja yang mengacu pada SKKNI, agar setiap tenaga kerja khususnya tukang plester dapat memahami dan menerapkan SKKNI tersebut.

2) Diharapkan tenaga kerja tukang plester di kota palu untuk mengikuti pelatihan agar mendapatkan sertifikat keterampilan, sehingga lebih meningkatkan kompetensinya

\section{Daftar Pustaka}

[1] Presiden Republik Indonesia, Undang-Undang Republik Indonesia Nomor 2 Tahun 2017 Tentang Jasa Konstruksi, Jakarta: Sekretariat Negara, 2017.

[2] Kompas.com, Hanya 720.000 dari 8,1 Juta Tenaga Konstruksi yang Bersertifikat, https://properti.kompas.com/read/2018/07/30/1619201 21/hanya-720000-dari-81-juta-tenaga-konstruksiyang-bersertifikat, diakses 11 Agustus 2018.

[3] I. Kodri, H. Fitriani, and I. Juliantina, "Analisis Pengaruh Pelatihan dan Sertifikasi terhadap Produktivitas Pekerja," Media Komunikasi Teknik Sipil, vol. 24, no. 1, p. 9, 2018.

[4] G. Vitri and D.I. Mazni, "Deskripsi Sertifikasi Kompetensi Tukang Lokal di Provinsi Sumatera Barat", Jurnal Rab Construction Research, vol. 3, no 1, p. 284, 2018.

[5] M.B. Wineke, V. Rismila, P. Nugraha, and T. E. Tumbelaka, “Aspek-Aspek Yang Mendukung Peningkatan Kinerja Tukang Dalam Proyek Konstruksi di Surabaya", Jurnal Dimensi Pratama Teknik Sipil, vol. 7 , no. 2 , p. 217,2018

[6] S.A. Nugraha, W. Mawardi, and F. Purwangka, "Identifikasi KompetensiKerja Pada Area DockingKapal di Ppn Palabuhanratu, Kabupaten Sukabumi Jawa Barat", Jurnal Ilmiah Samudra Akuatika, vol. 2, no. 1, p. 23, 2018

[7] B. Haryadi, "Kompetensi Tenaga Kerja Konstruksi Dalam Menghadapi Era Liberalisasi”, Inersia, vol. 6, no. 1 , p. 33, 2010.

[8] P. Suartanaa, R.J.M. Mandagi, and D. Wilar, "Pengaruh Pengetahuan Keselamatan dan Kesehatan Kerja (K3) Terhadap Perilaku Pekerja dan Kecelakaan Kerja Pada Proyek di DS LNG Kabupaten Banggai Propinsi Sulawesi Tengah", Rekonstruksi Tadulako: Civil Engineering Journal on Research and Development, vol. 2, no. 1, p. 15, 2021.

[9] A. Gunasti, "Penilaian Standar Kompetensi Kerja Tukang Besi/Beton Pada Proyek Konstruksi di 
Kabupaten Jember", Jurnal Rekayasa Tenik Sipil Universitas Madura, vol. 2, no. 2, p. 12, 2017.

[10] Presiden Republik Indonesia, Undang -Undang Republik Indonesia Nomor 13 Tahun 2003 Tentang Ketenagakerjan, Jakarta: Sekretariat Negara, 2003.

[11] Kementrian Pekerjaan Umum, Standar Kompetensi Kerja Nasional Indonesia (SKKNI) Tukang Plester, Jakarta: Yayasan Badan Penerbit PU, 2016.

[12] N. Sudjana and Ibrahim, Penelitian dan Penilaian Pendidikan, Bandung: Sinar Baru Algensindo, 2009.
[13] M. Ali, Penelitian Kependidikan Prosedur dan Strategi, Bandung: Angkas, 1993.

[14] I. Maulana, R. Arthur, and Daryati, "Kualitas Tes Kompetensi Tukang Aci dan Plesteran Berdasarkan SKKNI", Jurnal Pendidikan Teknologi dan Kejuruan, vol. 16 no. 2, p. 149, 2019.

[15] Prasetyo, "Kompetensi Tenaga Terampil Konstruksi di Smk Kartika V-1 Balikpapan”, Kurva S, vol. 1, no. 7, p. 1, 2019. 